\title{
Nursing Staffing, Nursing Workload, the Work Environment and Patient Outcomes
}

Christine Duffield, PhD

Professor of Nursing and Director, Centre of Health Services Research, Faculty of Nursing, Midwifery and Health, University of Technology, Sydney, PO Box 123, Broadway, Sydney, NSW, 2007, Australia.

au

Donna Diers, PhD

Professor Emerita, Yale University School of Nursing, New Haven, Connecticut, and Adjunct Professor, Faculty of Nursing, Midwifery and Health, University of Technology, Sydney, Australia.

Linda O'Brien-Pallas, PhD, FCAHS

Professor, University of Toronto, Lawrence Bloomberg, Faculty of Nursing

CHSRF/CIHR National Chair, Nursing Health Human Resources

Co-Principal Investigator, Nursing Health Services Research Unit (University of Toronto site)

Chris Aisbett, BSc

Director, Laeta Pty Ltd, Randwick, NSW 2031, Australia

Michael Roche, MHSc

Lecturer, Faculty of Nursing, Midwifery and Health, University of Technology, Sydney, Australia

Madeleine King, BSc(Hons), DipMedStat, PhD

Cancer Australia Chair in Cancer Quality of Life, University of Sydney, Australia

Kate Aisbett, BSc

Director, Laeta Pty Ltd, Randwick, NSW 2031, Australia

\section{Acknowledgment}

This research was funded by New South Wales Health. The views expressed in this article are the authors' and do not necessarily reflect the views of the funding organization. The authors wish to acknowledge the support given this research by the following individuals and organizations: the NSW Health Nursing and Midwifery Office, in particular Adjunct Professor Debra Thoms, Adjunct Professor Judith Meppem, Adjunct Professor Kathy Baker, Professor Mary Chiarella, Adjunct Professor Joan Englert, Ms Marianne Goodwin and Dr Cecilia Lau; Dr Sping Wang and Dr Xiaogiang Li of the Nursing Health Services Research Unit, University of Toronto; Dr Barbara McCloskey; Ms Nancy van Doorn; Ms Christine CatlingPaull; the Human Resources and Information Technology Departments across the NSW public health system; and the many nurses who participated in this study.

Running head title: Nursing, work environment, patient outcomes

Key words: Staffing/scheduling/turnover, Quality assurance/patient safety, Health Manpower, Health care delivery, Recruitment/retention 


\section{Abstract}

Nurse staffing (fewer RNs), increased workload and unstable ward environments were linked to negative patient outcomes including falls and medication errors on medical/surgical wards in a mixed method study combining longitudinal data (5 years) and primary data collection. 


\section{Nursing Staffing, Nursing Workload, the Work Environment and Patient Outcomes}

The New South Wales (NSW; Australia) Health Department commissioned a study in 2003 to help the government identify strategies for improving the effectiveness and efficiency of nurse staffing in its hospitals. Building on international research in this area, the investigators designed a study to examine the relationship of nurse staffing and workload, in the context of the work environment, to patient outcomes at the ward level (Duffield, et al., 2007). We took advantage of a rich administrative data depository in NSW and combined it with primary ward-level data collection. At the time the study was designed, there were only a few small ward-level studies representing efforts to link nurse staffing, workload, the working environment and patient outcomes in some configuration.

The methodological conundrum in finding data to measure these concepts is that data to bring them all together potentially exist only at the individual hospital level. In general, single sample studies are a weak source of evidence for public policy making. This is a problem if the purpose of the study is to contribute to health policy, as was the case here. Researchers in the United States have discovered that nursing resource data (staffing, skill mix, nurse/patient ratios) have to be estimated from publicly available sources that are sometimes questionable (Kovner \& Gergen, 1998; Needleman, Buerhaus, Mattke, Stewart, \& Zelevinsky, 2001, 2002). Further, some aspects of workload such as patient turnover cannot be obtained except at the local level, and although casemix (Diagnosis Related Groups - DRGs) as a component of workload is a feature of administrative datasets, it is never available in concurrent data at the ward level because DRGs are only assigned after discharge. The ward working environment is impossible to measure directly except with primary data collection.

Patient outcomes can be measured in large administrative datasets as mortality or length of stay. Needleman et al. $(2001,2002)$ used the International Classification of Diseases (ICD) coding in publicly available administrative data to define clinical Outcomes Potentially Sensitive to Nursing (OPSN). However, adverse outcomes of special interest to nurses, such as falls and medication errors, cannot be obtained in most large administrative datasets to any reliable degree. Although country, state and hospital level analyses have been useful, the ward is the place where the effects of government or institutional decisions about the allocation of resources come to rest. Ward-level data are generally not available in large administrative datasets. For this study we were able to combine longitudinal retrospective analysis of the NSW administrative data with cross- 
sectional primary ward level data collection from nurses and patient/ward records. The focus was on medical/surgical nursing wards, which is where the majority of hospital nurses work, and which have been relatively understudied.

\section{Conceptual Framework}

There are a number of conceptual frameworks that link nursing as a resource, skill mix and/or nursing education, to nurse or patient outcomes through some kind of pathway that includes the working environment (e. g. Aiken, Sochalski, \& Lake, 1997; Leiter \& Laschinger, 2006; O'Brien-Pallas, et al., 2001; Tourangeau, et al., 2007). To guide this study we built on the Patient Care System Model (O'Brien-Pallas, et al., 2001, 2002; O'Brien-Pallas, et al., 2004) because it includes nurse variables (staffing, skill mix, job satisfaction), workload (patient acuity, patient turnover, length of stay) and the working environment (including environmental complexity), believed to impact on patient outcomes. The model does not predict exact chains of relationships among these concepts, but was useful for organizing primary data collection and analysis. As linking administrative data with primary data on the ward working environment to our knowledge had not been done previously, we viewed the study as exploratory.

\section{Literature Review}

Research in this field has reached the point at which there are systematic literature reviews (Dall, Chen, Seifert, Maddox, \& Hogan, 2009; Kane, Shamliyan, Mueller, Duval, \& Wilt, 2007) and other collections of studies (Hyun, Bakken, Douglas, \& Stone, 2008; Unruh, 2008) of relationships among various combinations of nurse staffing (numbers and skillmix), workload, work environment, and patient outcomes. Kane et al. (2007) concluded that evidence on the positive effect of higher proportions of RNs on patient outcomes in intensive care and surgery was strong and consistent. Higher RN staffing was associated with less hospital mortality, failure to rescue, cardiac arrest, hospital acquired pneumonia, and fewer other adverse events. Findings were stronger in ward level studies than hospital, state, or country level studies. They concluded that future research should include additional factors such as the organization of nursing units and staff, patient characteristics and medical practice patterns in large multi-center studies. They did not mention workload components or turnover. Dall et al. (2009) concluded that when nurse staffing levels increase, risk of nosocomial complications, ranging from sepsis to falls and including failure to rescue and length of stay, are decreased. Workload and the working environment 
were not considered. In a meta-analysis of studies of critical care units, Numata et al. (2006) concluded that nurse staffing levels did not affect hospital mortality, but noted that measuring exposure status (how long patients had been in ICU and therefore how much mortality could attach to ICU stay) was a methodological challenge. Neither workload nor the ward working environment were discussed.

Studies of legislatively imposed minimum nurse staffing ratios have been reviewed by Lang, Hodge, Olson, Romano and Kravitz (2004), who concluded that there is no support for minimum nurse-patient ratios for acute care hospitals, especially when skill mix and patient casemix are not considered. Total nursing hours did "appear to affect some important patient outcomes" (p. 326). There is no direct measurement of workload or the working environment in the studies reviewed because the authors assume that a more favorable (lower) nursing/patient ratio implicitly creates a more positive workplace out of either equity of patient assignment or adequate staff.

In the State of the Science paper on nursing performance measurement, Needleman, Kurtzman and Kizer (2007) concluded that the Nursing Quality Forum (NQF) measures are a good beginning, there is much more to be done to develop measures that speak to nursing and to stakeholders such as consumers, purchasers, and, we would add in an international context, government. They do not specifically mention workload nor the working environment. In addition to these reviews, there is substantial research evidence that supports relationships among nurse staffing, workload, working environment, and patient outcomes, although the terminology used among studies in this area is not standard. Table 1 shows the major concepts of interest and the relevant variables discussed in this paper. The placement of some measures in categories or data levels is sometimes arbitrary. For instance, skill mix could be in the workload column if a lower percentage of RNs increases their workload through the necessity for supervision of other staff; patient outcomes can be collected in primary data collection including chart review, but are also available in administrative data, albeit with questions of reliability and validity. 


\begin{tabular}{|c|c|c|c|c|}
\hline & Nurse Staffing & Nursing Workload & Working Environment & Patient Outcomes \\
\hline 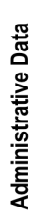 & $\begin{array}{l}\text { - Number of RN's } \\
\text { - Nursing hours worked } \\
\text { - Nursing hours per patient day } \\
\text { - Skill mix (\% RN) }\end{array}$ & $\begin{array}{l}\text { - Patient turnover (churn) } \\
\text { - } \quad \text { Case mix (number of DRGs/ward) }\end{array}$ & $\begin{array}{l}\text { - Rural/urban } \\
\text { - Ward type }\end{array}$ & $\begin{array}{l}\text { - Length of stay (LOS) } \\
\text { - Failure to rescue } \\
\text { - Outcomes Potentially Sensitive to } \\
\text { Nursing (OPSN) }\end{array}$ \\
\hline 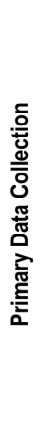 & $\begin{array}{l}\text { - Percent BSN } \\
\text { - Presence of CNS } \\
\text { - Presence of nurse educator } \\
\text { - } \text { Nurs of experience of nursing staff } \\
\text { - Percent nurses on permanent } \\
\text { - } \text { Pentracts } \\
\text { this ward } \\
\text { - Percent nurses practicing at high } \\
\text { clinical level }\end{array}$ & $\begin{array}{l}\text { - Patients per bed } \\
\text { - } \quad \text { dours of care required per patient } \\
\text { day } \\
\text { - Nursing demand/supply } \\
\text { - } \quad \text { (hours of care required per } \\
\quad \text { patient day / nursing hours per } \\
\quad \text { patient day) } \\
\text { - Housekeeping support hours } \\
\text { - } \quad \text { Amount additional time needed for } \\
\text { patient care per shift }\end{array}$ & $\begin{array}{l}\text { - Organizational Factors } \\
\text { - } \quad \text { Nuctice control } \\
\text { - RN/MD relationships } \\
\text { - Nursing leadership } \\
\text { - } \quad \text { Resource adequacy } \\
\text { - Environmental complexity } \\
\text { - Perceptions of violence } \\
\text { - Job satisfaction } \\
\text { - Number patients waiting for care } \\
\text { - } \text { Nucility } \\
\text { - Clinical pathways } \\
\text { - Clinical/technical assistance on ward } \\
\\
\text { (PT, OT, etc) }\end{array}$ & $\begin{array}{l}\text { - Falls } \\
\text { - Medication errors } \\
\text { - Nursing tasks delayed } \\
\text { - Nursing tasks undone }\end{array}$ \\
\hline
\end{tabular}

a UTI; Decubitus; Pneumonia; DVT/PE; GI bleed; CNS complications; Sepsis; Shock/cardiac arrest; Surgical wound infection; Pulmonary failure; Physiological/metabolic derangement (Needleman, et al., 2001).

Nurse staffing and patient outcomes. Lower levels of RN staffing are associated with higher rates of Outcomes Potentially Sensitive to Nursing (OPSN) - urinary tract infections, pneumonia, shock and cardiac arrest, upper gastrointestinal bleeding, failure to rescue - and length of hospital stay (LOS) in both medical and surgical patients treated in hospitals in US Medicare and other publicly available administrative data (Needleman, et al., 2001, 2002). These researchers creatively used administrative data as ICD-9 codes and DRGs, to define clinical outcomes beyond mortality. Similarly, Kovner and Gergen (1998) found a significant inverse relationship between number of RNs per adjusted patient day and urinary tract infections and pneumonia after surgery. Both studies used American Hospital Association (AHA) data for nursing staffing. AHA data come from hospital- selfreports and cannot be tracked to the nursing unit. In addition, AHA has changed its definitions of nurse staffing from time to time to include or not include unlicensed personnel, depending on the agenda of the Association at the time.

Increased skill mix (\%RN) but decreased nursing hours per patient day in the presence of the "chaotic" (p. 1140) work environment created by healthcare reform in New Zealand (NZ; including decreased LOS) created significant increases in the 11 OPSN measured (McCloskey \& Diers, 2005). Nursing data came from a questionnaire attached to annual practice certificates required by the NZ government and the policy context provided an external source for measuring the working environment. 
Tourangeau et al. (2007) found that a $10 \%$ increase in nurse-reported adequacy of staffing was associated with 17 fewer deaths/1000 discharged patients. A United Kingdom (UK) study showed that hospitals with the highest patient-to-nurse (RN) ratios had 26\% higher mortality (Rafferty, et al., 2007). Staffing data were obtained from a survey of clinical nurses aggregated to the hospital level. Aiken, Clarke, Cheung, Sloane and Silber (2003) showed that surgical patients experienced lower mortality and failure to rescue rates in hospitals with higher proportions of nurses educated at the baccalaureate level or higher. In an examination of skill mix at the ward level, Canadian researchers (McGillis-Hall, Doran, \& Pink, 2004), using staffing data collected by a survey of the managers of 77 wards in Ontario, concluded that a higher proportion of RNs on medical and surgical wards was associated with positive outcomes such as lower rates of medication errors and hospitalacquired infections.

Finally, the study by Sales et al. (2008) on the US Veterans Administration data found that while RN staffing was not associated with in-hospital mortality for patients with an ICU stay, it was for non-ICU patients; increased RN staffing was associated with decreased mortality risk. These authors note that the hospital level data did not consider the mix of patients at the unit level, but did include actual staffing hours.

In summary, researchers in several countries have found that increased nursing hours and a richer skill mix (more RNs) improve patient outcomes. Most of this work has been undertaken at the hospital rather than the ward level and has used estimates or self reported staffing.

Nursing workload. Measures of workload as used in the literature includes characteristics of patients (e.g. casemix) and patient turnover (Unruh \& Fottler, 2006), as well as patient acuity/intensity (Graf, Millar, Feiteau, Coakley, \& Erickson, 2003; Hyun, et al., 2008). Aiken, Clarke, Sloane, Sochalski et al. (2001) surveyed nurses in five countries and found that one result of increased workload was that basic nursing interventions were left undone. Being unable to provide the required level of patient care was linked to lower job satisfaction and staff retention.

Staff shortages and the resulting increased workload have led to concerns about the quality of health care provided to patients in surveys of nurses and as reported in literature reviews (Aiken, Clarke, Sloane, \& Sochalski, 2001; Haberfelde, Bedecarre, \& Buffum, 2005; Lankshear, Sheldon, \& Maynard, 2005). In the UK, Adams, Lugsden, Chase, Arber, and Bond (2000) found when skill mix was decreased, nurses reported increased intensity of work with constant heavy workloads, significant role changes and pressures to broaden the 
range of nursing skills, and more overtime. However, workload pressures and inadequate staffing can sometimes be offset by a positive team nursing environment within a ward (Sexton, et al., 2006). Workload was not directly measured in these studies.

O'Brien-Pallas et al. (2004) collected the hours of care required for patients at the unit level with the PRN-80 (Programme de Recherche en Nursing; Chagnon, Audette, Lebrun, \& Tilquin, 1978) and divided it by nurse worked hours to create a new metric of workload: nursing demand/supply. In that study of six Canadian hospitals it was found that when nursing demand/supply levels exceeded $80 \%$, the number of negative outcomes increased not only for patients, but also for nurses and hospitals. In a study using administrative data from Pennsylvania hospitals, Unruh and Fottler (2006) calculated indices of patient turnover using LOS data at the hospital level over time, and AHA survey data to determine patient days of care. They found that using nurse-topatient ratios underestimated nursing workload and overstated RN staffing levels. They concluded that patient turnover should be included in assessing workload in future research.

At the ward level, casemix (e.g. higher number of DRGs by nursing unit) has been associated with longer LOS (Diers \& Potter, 1997; Duffield, Diers, Aisbett, \& Roche, 2009). Number of "off-service" patients (Czaplinski \& Diers, 1998) has been associated with more mortality and longer LOS. Patient age and complexity of patients (e.g. alcohol withdrawal, confusion, tracheostomy; Beglinger, 2006) have been used to justify nurse staffing.

Working environment and patient outcomes. Aiken's canonical study of Magnet hospitals, known as "good places for nurses to work" (Aiken, Smith, \& Lake, 1994), used US Medicare data to link the working environment and patient outcomes. There was a $4.6 \%$ decrease in mortality comparing Magnet with matched non-magnet hospitals.

A number of investigators have used the Revised Nursing Work Index (Aiken \& Patrician, 2000; Kramer \& Hafner, 1989), as a measure of the work environment. The NWI-R grew out of the Magnet Hospital research, and measures nurse autonomy, control over practice, nurse-doctor relations, nursing leadership, and resource adequacy. Wards with higher subscale scores demonstrated higher patient satisfaction (Vahey, Aiken, Sloane, Clarke, \& Vargas, 2004), lower nurse emotional exhaustion (Leiter \& Laschinger, 2006) and lower incidence of needlestick injuries (Clarke, 2007). In the one study using NWI-R at the ward level (Boyle, 2004), nurses' perceptions of control of practice, autonomy/collaboration, and continuity/specialization were associated with a 
lower incidence of urinary tract infections, pneumonia, cardiac arrest, and shorter length of stay. Higher levels of nurse manager support were associated with lower rates of pressure ulcers and mortality, yet higher rates of failure to rescue. Improved collegial relationships between nurses and doctors, along with better educated nurses and richer skill mix have been linked with decreased patient mortality (Estabrooks, Midodzi, Cummings, Ricker, \& Giovannetti, 2005). Hospitals with poor care environments had a higher percentage of nurses reporting high burnout levels and dissatisfaction with their jobs (Aiken, Clarke, Sloane, Lake, \& Cheney, 2008). Selfreported collaboration between medical intensive care unit nurses and physicians was linked to improved patient outcomes (Baggs, et al., 1999).

More complex care environments also have an impact on patient outcomes. Using the Environmental Complexity Scale (ECS) O'Brien-Pallas et al. (2004) found high levels of environmental complexity were associated with more medical consequences for patients. In that study, nurses' perceptions of ward violence (emotional abuse, threats or actual assault) were associated with delayed nursing interventions.

No study has been designed to put together nurse staffing, nursing workload, the working environment and patient outcomes at ward level in one design because data have not been available on all four aspects of the model in the same settings. This is what we attempted to do. Based on the literature and the research objectives requested by NSW Health, the research questions were:

1. Has nursing workload (measured as inpatient acuity, shorter length of stay, patient turnover and casemix), and skill mix increased over time?

2. What are the relationships among patient outcomes (OPSNs, falls and medication errors), nursing skill mix, nursing workload and the nursing work environment?

\section{Method}

Setting

New South Wales is the most populous of Australia's seven States and Territories and contains a third of Australia's population of 21.5 million (Australian Bureau of Statistics, 2008). The State is divided into Area Health Services (AHS), 17 at the time the study began, 8 when it finished. Commonwealth and State 
governments fund Area Health Services on a population-based funding model. Data were obtained from the public hospital system (61\% of all hospital discharges; Australian Institute of Health and Welfare, 2008).

Public hospitals in NSW are categorized for budget/payment purposes by casemix similarity (relative proportions of Australian Revised Diagnosis Related Groups - AR-DRGs; Aisbett, 1999). The eight acute care hospital peer groups were collapsed into four for the present study: A, Principal/Major Referral and Specialist; B1, Major Metropolitan; B2, Major Regional; C, Other Regional Hospital. All public hospitals in NSW contribute their administrative discharge data to a central resource, the Health Information Exchange (HIE). For the present study five fiscal years of data (2001-2006) for the 80 public hospitals were obtained.

\section{Design and Samples}

A design combining longitudinal retrospective and concurrent cross-sectional methods was employed to analyze five years of administrative data and one overlapping year of primary ward-level data. The study was approved by the Human Research Ethics Committee of the University of Technology, Sydney, and by 14 other ethics committees at NSW Health and Area Health Services. The study consisted of two arms: (1) longitudinal retrospective patient discharge and nursing payroll/scheduling data acquired from the HIE and Area Health Services for Financial Years (FY) 2001-2006; and (2) primary data collected from 80 randomly selected patient wards in 19 hospitals from FY 2004-2005 (Figure 1). 


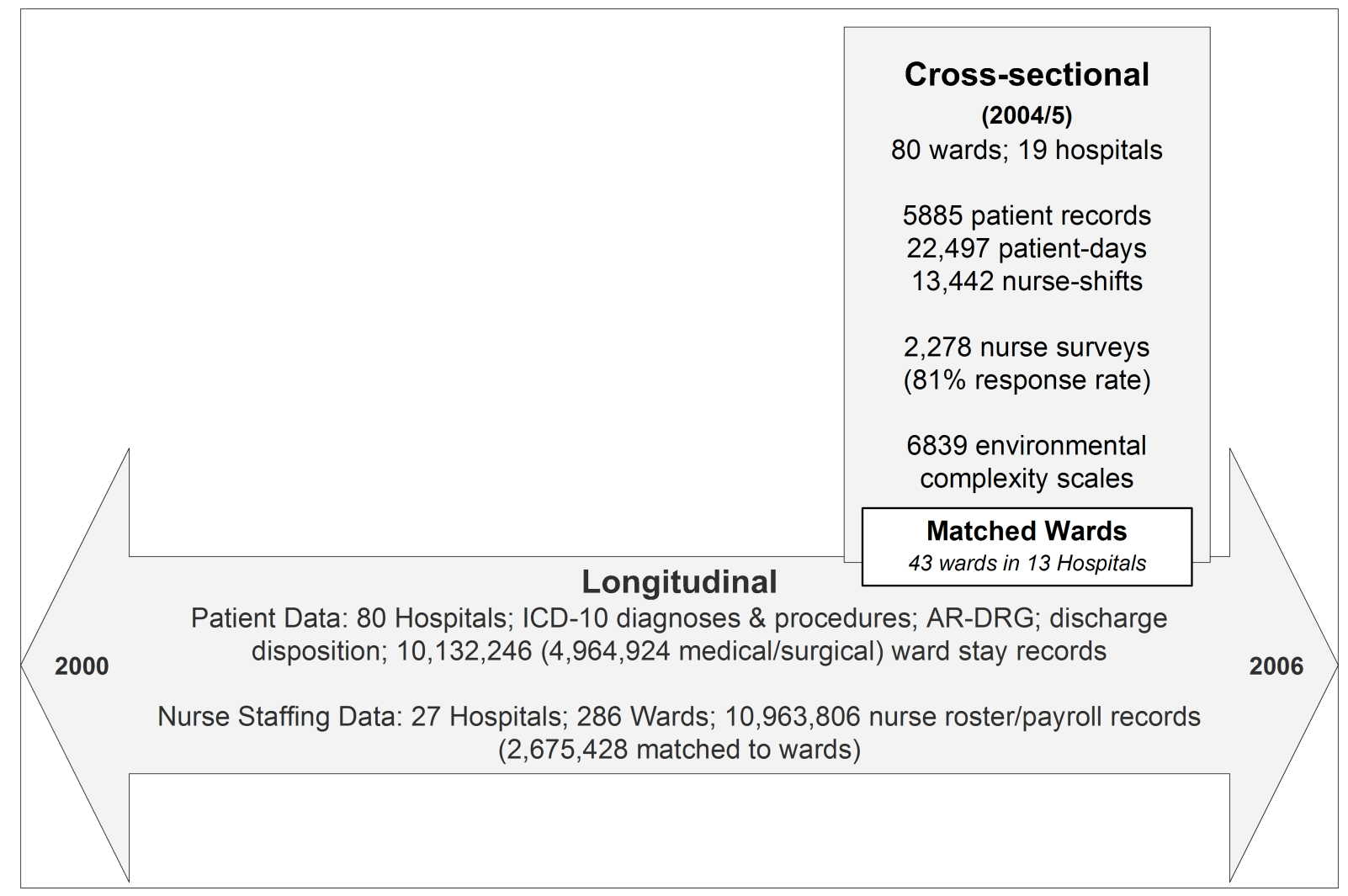

The HIE database consisted of encounter-level patient data including patient demographics. AR-DRGdefined clusters of units were defined as "medical", "surgical", "mixed" (combined medical and surgical), and "other" (ICU, ED). Payroll/scheduling data were held by all AHSs. Of the 80 hospitals, 27 (35\%) provided useable workforce data for 286 wards. As these administrative data had never been used for analysis before, considerable effort was required to locate, produce, audit, and reconcile them. For example, hospitals do not use uniform codes for type of nursing shift, for categories of personnel, or even for what nursing units are called. Ward "11A" in HIE data might have been "Curtin South" in payroll data. One person-year of effort was required in the reconciliation process. Following the exclusion of annual leave and other "non-productive" shifts, a total of $2,675,428$ nurse roster/payroll records could be matched to wards.

The categories of caregivers examined were RN; Clinical Nurse Specialist (CNS: unique to NSW - a personal grade awarded to individual nurses on the basis of expertise in a specialty demonstrated by qualifications and/or experience; NSW Health, 2008); Enrolled Nurse (EN: equivalent to LVN/LPN), Assistants in Nursing (AIN): and Trainee Enrolled Nurses (TEN: 1 year [6 months paid] vocational training). The analysis did 
not include non-caregiver staff such as Clinical Nurse Educators (CNE), Clinical Nurse Consultants (CNC: roughly equivalent to Clinical Nurse Specialists in the USA) or Nursing Unit Managers (NUM).

In the cross-sectional component, a random sample of wards stratified by hospital peer group was drawn from acute-care hospitals. Eighty (80) wards were selected in 19 hospitals. "Medical" and "surgical" units were defined using hospital-provided definitions. Patient (all hospitalized patients for the applicable weeks) and ward data were collected by trained nurse data collectors for 7 days on all shifts. Because of different definitions of "medical/surgical" between the longitudinal and cross-sectional parts of the study, only 43 nursing wards could be matched across longitudinal and cross-sectional data (Figure 1).

Data collection and measurement. The longitudinal study used standard data field definitions for demographics, discharge disposition, length of stay, ICD-10 codes, and AR-DRGs.

Outcomes Potentially Sensitive to Nursing (OPSN), originally defined by Needleman et al. (2001), are clinical conditions defined by ICD-9 codes and US DRGs recorded in the discharged patient record. Australia and NZ have used the same ICD-10 and AR-DRG coding rules for many years. Therefore we used McCloskey's NZ translation of ICD-9 to ICD-10 for this study (McCloskey \& Diers, 2005). There were 11 OPSN: urinary tract infection, decubiti, pneumonia, deep vein thrombosis/pulmonary embolism, ulcer/gastrointestinal bleeding, central nervous system complications, sepsis, shock/cardiac arrest, surgical wound infection, pulmonary failure and physiological/metabolic derangement. The OPSN excluded the Major Diagnostic Categories (MDC) for maternity, newborn, mental illness, and substance abuse. All cases under the age of 18 were excluded, as well as all cases with a length of stay $<1$ day or over 90 days (outliers). The OPSN algorithms create cohorts of riskadjusted clinical groups. For example, the OPSN for decubiti excludes cases with ICD codes for quadra- or paraplegia, and all cases with principal diagnoses of skin conditions. Failure to rescue (Silber, Williams, Krakauer, \& Schwartz, 1992) was measured as mortality following sepsis, pneumonia, GI bleeding, or shock. Table 2 shows the primary data collection instruments with their characteristics and reliability/validity information. Permission to use all instruments was obtained from the original authors. 
Table 2 Data Collection \& Measurement

\begin{tabular}{|c|c|c|c|}
\hline Instrument & Details & Present study statistics & Administration \\
\hline $\begin{array}{l}\text { Revised Nurse } \\
\text { Work Index } \\
\text { (NWI-R) }\end{array}$ & $\begin{array}{l}49 \text { items. Measures organizational attributes } \\
\text { leading to positive patient, nurse and institutional } \\
\text { outcomes. Subscales: nurse autonomy; nurse } \\
\text { control; nurse-physician relations; leadership; } \\
\text { resource adequacy (Aiken \& Patrician, 2000). }\end{array}$ & $\begin{array}{l}\text { Five subscales; Cronbach's } \\
\text { alpha: autonomy }(0.74) ; \\
\text { control over practice }(0.77) ; \\
\text { nurse-physician relations } \\
(0.83) ; \text { leadership }(0.80) ; \\
\text { resource adequacy }(0.80) \text {. }\end{array}$ & $\begin{array}{l}\text { Administered } \\
\text { once to each } \\
\text { nurse. }\end{array}$ \\
\hline Nurse Survey & $\begin{array}{l}29 \text { items. Measures nurses' perceptions about } \\
\text { the work environment and quality of care on the } \\
\text { unit. Also demographics, job satisfaction and } \\
\text { intent to leave. Specific items on perception of } \\
\text { emotional abuse or physical violence. Adapted } \\
\text { from Aiken et al., (2001); O'Brien-Pallas et al., } \\
\text { (2004) }\end{array}$ & & $\begin{array}{l}\text { Administered } \\
\text { once to each } \\
\text { nurse. }\end{array}$ \\
\hline $\begin{array}{l}\text { Environmental } \\
\text { Complexity } \\
\text { Scale } \\
\text { (ECS) }\end{array}$ & $\begin{array}{l}32 \text { items. Measures unanticipated delays in } \\
\text { response to others leading to resequencing of } \\
\text { work; unanticipated delays due to changes in } \\
\text { patient acuity; characteristics \& composition of } \\
\text { the caregiver team; includes nursing } \\
\text { interventions delayed or left undone at shift end. }\end{array}$ & $\begin{array}{l}\text { Cronbach's a: resequencing } \\
\text { of work ( } 0.73) \text {; unanticipated } \\
\text { changes in patient acuity } \\
(0.81) ; \text { composition and } \\
\text { characteristics of the care } \\
\text { team }(0.56) \text {. }\end{array}$ & $\begin{array}{l}\text { Collected from } \\
\text { nurses once } \\
\text { each shift. }\end{array}$ \\
\hline $\begin{array}{l}\text { PRN-80 } \\
\text { Workload } \\
\text { Measure }\end{array}$ & $\begin{array}{l}214 \text { indicators or tasks nurses complete during a } \\
24 \text { hour period; each indicator has a standard } \\
\text { point time point value, each point represents } 5 \\
\text { minutes. (Chagnon et al., 1978). }\end{array}$ & Inter-rater reliability: $87.2 \%$. & Patient record. \\
\hline $\begin{array}{l}\text { Daily Ward } \\
\text { Staffing Profile }\end{array}$ & $\begin{array}{l}\text { Nurse staffing and skill mix for every shift every } \\
\text { day. Includes number/mix of staff, number of } \\
\text { agency/casual staff, nurse absenteeism, number } \\
\text { of staff floated to/from the unit, number of staff on } \\
\text { orientation, nurse-patient ratios. }\end{array}$ & & Ward rosters. \\
\hline $\begin{array}{l}\text { Adverse Events } \\
\text { Profile }\end{array}$ & $\begin{array}{l}\text { Number of falls, medication errors, number of } \\
\text { medications given } 30 \text { minutes outside prescribed } \\
\text { time. }\end{array}$ & & $\begin{array}{l}\text { Adverse event } \\
\text { reporting system; } \\
\text { patient record. }\end{array}$ \\
\hline $\begin{array}{l}\text { Unit/Hospital } \\
\text { Profile }\end{array}$ & $\begin{array}{l}\text { Unit/hospital size, use of clinical pathways and } \\
\text { standard nursing care plans, presence of an } \\
\text { educator, hours of cleaning/clerical/auxiliary } \\
\text { support available to the unit. }\end{array}$ & & $\begin{array}{l}\text { Ward nursing } \\
\text { manager by } \\
\text { interview. }\end{array}$ \\
\hline
\end{tabular}

Nurse data collectors gathered standard information from ward and patient records on bed occupancy,

falls, and medication errors, data that were not available in administrative databases. Time-based medication errors (> 30 minutes) were collected from the ward adverse events reporting software or by ward incident reports where this software was not in use. Data on medical adverse events (urinary tract infections, hospital acquired pneumonia, surgical site infection, decubiti, and deep vein thrombosis [DVT]) were collected from the concurrent patient record.

Statistical approaches. As the longitudinal part of the study was primarily descriptive, data analysis used counts, means, and ranges. Hospitals supplied different amounts of nursing staffing data for different time periods. These time snippets were translated to "ward-months." Where associations were sought regarding 
hospital or ward type, the binomial distribution combined with Chi Square or Fisher's Exact probability test provided a conservative estimate of ward-months of data that could be counted as increase or decrease by ward (the binomial) in the variable of interest. Hospital peer group and ward classification (medical, surgical, mixed, or other by DRG volume) were used for risk adjustment. Linear regression was used to link nurse staffing to patient outcomes as OPSN. The fixed effect model used on OPSN rates was adjusted for AR-DRG casemix. The indirect method was used at hospital level. Data were then analyzed using Weighted Least Squares with the expected number of events as weights.

Cross-sectional data were exported to SPSS version 12 (SPSS Inc., 2003) for analysis. Missing patient or nurse data were imputed as the ward mean. Where more than $10 \%$ of data were missing, that variable was not used in regression analyses. Complete staffing data were not available on three wards; they were excluded from analyses using staffing data.

Patient outcomes in cross-sectional data were measured as counts per ward. Nurse and individual patient data were therefore aggregated to the same (ward) level for analysis. For all regression modeling, explanatory variables were added in sequence and the properties of each newly expanded model were compared to the previous one using the -2 Log Likelihood value. In the case of low numbers of outcomes, Poisson distributions provided the basis for statistical analysis.

\section{Results}

\section{Nurse Staffing}

With total nursing time on the ward as the denominator, the average skill mix across hospitals for medical, surgical, or general wards for the 5-year period showed $68.4 \% \mathrm{RN}, 7.4 \% \mathrm{CNS}, 20.4 \% \mathrm{EN}$, and $3.8 \%$ AIN/TEN. With the exception of day units, the proportion of RNs (including CNS) was lowest in general $(70.3 \%$ RN and $7.3 \%$ CNS), medical (65.4\% and $7.2 \%$ ) and surgical (68.5\% and $7.6 \%)$ units, and highest in specialty units.

Over the 5 years, there was a significant increase in AIN/TEN hours relative to total nursing hours in the metropolitan hospitals and decreased RN hours in general wards across all hospital peer groups. There was a significant increase in RN hours in "other" ward types, which included ICU, ED, and specialty wards. CNS hours 
were significantly decreased in metropolitan teaching/referral and rural hospitals, and significantly decreased in medical, surgical and "other" ward types across hospital peer groups (data not shown).

The cross-sectional findings amplified these findings. There was a considerable range in skill mix, from a low of about $45 \%$ RN on one ward to two wards with $100 \%$ RN staff. Fifteen (20\%) wards had greater than $35 \%$ EN hours. Thirty-two (42\%) wards did not employ any nurses other than RN and EN.

Per ward, the average proportion of hours worked by full-time staff was $55.5 \%(S D=12.77)$. Casual/agency staff hours averaged $17 \%$ across the 77 wards. One ward had $47.8 \%$ casual and agency hours worked; one ward employed no casual or agency staff. Job satisfaction was fairly high, with $67 \%$ of the sample moderately or very satisfied with the present job.

\section{Nursing Workload}

Average hospital LOS dropped from $3.26(S D=1.44)$ days to $3.23(S D=1.51)$ across the five years. However, the average amount of time spent by patients on an individual ward was only about two thirds of the hospital length of stay (2.08 days, $S D=1.62)$, suggesting that patients were visiting a number of wards during an episode of care. Excluding day cases, the average number of wards seen by each patient increased over the 5 years, from $2.10(S D=.53)$ to $2.26(S D=.68)$.

In the cross-sectional study, the actual nursing hours per patient day (NHPPD) varied around a mean of 5.12 hours (range $2.7-10.9$ ). Scores for the PRN-80 acuity instrument, which determines the hours of care required for patient care for 24 hours using data from the medical record, showed considerable variability. The average requirement per day was 6.20 hours $(S D=1.55)$ but the difference between the minimum and maximum requirements per ward day was 35 minutes to 6 hours, 45 minutes.

The nursing demand/supply factor, an estimate of how much workload exceeds demand, was calculated by dividing the required hours of care from PRN- 80 by the hours of care provided (O'Brien-Pallas, et al., 2004). A demand/supply factor of 100 indicates balance between workload and staffing. Over all ward days, the average figure was $124.0(S D=33.78)$. Only one quarter of the wards were on balance at 100 or less. One ward's demand/supply figure was 250.29 . Nurse to patient ratios showed a range of 6.13 to 9.90 patients for all caregiver categories. The average number of patients to RN over 24 hours was $7.99(S D=2.31)$. 


\section{Nursing Work Environment}

On the NWI-R, control over practice and resource adequacy were correlated with demand/supply (-.311 and -.313 respectively, $p \leq .01)$. As the discrepancy between nursing demand and supply fell the perception of adequacy of resources and degree of control over practice rose.

Rates for perceptions of emotional or physical abuse were as follows: Physical assault ( $14.3 \%$ of respondents); threats of assault (20.8\%); and emotional abuse (38.7\%). Nearly all physical assaults (97\%) and threats of assault (94.6\%) were from patients and families, as was emotional abuse $(70.4 \%)$, but the latter was also reported from co-workers (16.3\%).

\section{Patient Outcomes}

Using the longitudinal sample of 286 wards with RN hours per patient hour as the independent variable, increased RN/CNS staff were associated with significantly $(p \leq .01)$ decreased rates of decubiti, pneumonia and sepsis. With RN/CNS hours as a proportion of nursing hours, an increase in RN/CNS hours was associated with significant $(p \leq .01)$ decreases in six OPSN: decubiti, GI bleeding, physiological/metabolic derangement, pulmonary failure, sepsis and shock.

In the cross-sectional study, medication errors (principally administration delays without consequences) were the most common adverse event at $15.8 \%$ of patients. Overall, $18.4 \%$ of patients experienced either a fall or medication error. As was the case with any measure of nursing ward variables, there was considerable variation in the rates across wards, from $0.0 \%$ to $71.4 \%$. There was an average of 28.5 ( $S D=4.98$ ) time-based medication errors per ward per 7-day sample.

Comforting and talking to patients was the task most frequently reported as undone (39.5\% of shifts) with back rubs and skin care (24\%), oral hygiene (19.3\%), teaching for patients and families (16.3\%), and documentation (15\%) next. Responding to patients' call lights (50.6\% of shifts), vital signs (37.8\%), medications or dressings, mobilization/turning (29.3\%), and administering PRN (as needed) pain medications (21.5\%) were the tasks most often reported delayed. Increased unanticipated changes in patient acuity, decreased resource adequacy, and decreased specialist nursing support were statistically related to tasks delayed or not done (data not shown). 
Rates of ward-measured (cross-sectional) medical consequences (UTI, pneumonia, surgical site infection, decubiti and DVT) were so low, probably because they were collected before the patient's hospitalization was complete, that they were not useful for further analysis.

Integrating Nurse Staffing, Workload, Work Environment and Patient Outcomes

Using regression statistics on the primary data collected, a greater number of falls was associated with the proportion of patients waiting for a care facility and the proportion of EN hours worked; a higher turnover of patients per day and more hours of care required per patient were linked to fewer falls. Increased medication errors were associated with more nurses experiencing a threat of violence and tasks delayed. More nurses working on their usual ward, more patients with planned admission, the presence of nurse educators and technical assistants (such as ECG technicians), larger wards, and more overtime were associated with fewer medication errors (Table 3).

Table 3 Poisson Regression on Patients per Ward with a Fall, Medication Error, or Time-based Medication Error

\begin{tabular}{|c|c|c|}
\hline Outcome & Variables & Coef. $^{*}$ \\
\hline \multirow{4}{*}{$\begin{array}{l}\text { Falls } \\
\text { (with \& without injury) } \\
\text { (Pseudo } R^{2}=.21 \text { ) }\end{array}$} & Proportion of patients waiting for care facility & 3.88 \\
\hline & Proportion of hours worked by enrolled nurses & 2.14 \\
\hline & Patients per bed & -5.18 \\
\hline & Mean hours of care required per patient day & -0.33 \\
\hline \multirow{8}{*}{$\begin{array}{l}\text { Medication Errors } \\
\text { (except time-based) } \\
\text { (Pseudo R² }=.26 \text { ) }\end{array}$} & Proportion of nurses that usually work on this ward & -1.99 \\
\hline & Proportion of patients with planned admission & -0.84 \\
\hline & Tasks delayed per shift & 0.45 \\
\hline & Nurse educator on ward & -0.37 \\
\hline & Technical assistance on ward & -0.26 \\
\hline & Total overtime reported by nurses per week & -0.09 \\
\hline & Number of beds on ward & -0.03 \\
\hline & Proportion nurses experiencing threat of violence & 0.01 \\
\hline \multirow{9}{*}{$\begin{array}{l}\text { Time-based } \\
\text { Medication Errors } \\
\text { (Pseudo } R^{2}=.43 \text { ) }\end{array}$} & Proportion of patients waiting for care facility & 2.27 \\
\hline & Patients per bed & 2.20 \\
\hline & Proportion of nurses that usually work on this ward & -3.79 \\
\hline & Clinical pathways in use & -0.22 \\
\hline & Nurse educator on ward & -0.18 \\
\hline & Hours of housekeeping support & -0.09 \\
\hline & Amount additional time needed for patient care per shift & 0.06 \\
\hline & Proportion of nurses experiencing physical violence & 0.04 \\
\hline & Proportion of nurses experiencing emotional abuse & 0.01 \\
\hline
\end{tabular}

\footnotetext{
*For a one unit change in the predictor variable, the difference in the logs of expected counts is expected to change by the respective regression coefficient Note. All $p$ values were $\leq .01$ with the exception of 'Proportion of hours worked by enrolled nurses' $p=.03$
} 
Time-based medication errors were associated with perceptions of physical violence, emotional abuse, the amount of additional time needed for patient care per shift, higher turnover of patients, and the proportion of patients waiting for a care facility. Fewer time-based medication errors were related to more nurses working on their usual ward, the use of clinical pathways, the presence of a nurse educator, and a higher number of housekeeping support hours per week.

Data from 43 wards in the cross-sectional study were matched to administrative data from the longitudinal study to provide OPSN rates. These rates had skewed distributions with a predominance of very low values (including zero). Poisson regression analyses on three of these outcomes showed similar associations to those found for falls and medication errors (Table 4). That is, in addition to nurse staffing variables (proportion of RN hours, nursing experience, part time hours worked), workload and working environment variables were associated with lower rates of two OPSN, central nervous system derangement, and UTI, as well as failure to rescue.

Table 4 Poisson Regressions on Patients per Ward with OPSNs

\begin{tabular}{|c|c|c|c|}
\hline Outcome & Variables & Coef. $^{*}$ & $p$ \\
\hline \multirow{3}{*}{$\begin{array}{l}\text { CNS } \\
\text { (Pseudo } R^{2}=.18 \text { ) }\end{array}$} & Proportion of nurses on permanent contracts & -5.20 & .02 \\
\hline & Proportion of nurses satisfied with current job & -3.99 & .04 \\
\hline & Proportion of nurses experienced physical violence & 0.03 & .05 \\
\hline \multirow{4}{*}{$\begin{array}{l}\text { UTI } \\
\text { (Pseudo R2 = .15) }\end{array}$} & Proportion of nurses practicing at high clinical level & -3.62 & $<.01$ \\
\hline & Proportion of patients with planned admission & -2.87 & $<.01$ \\
\hline & Proportion of nurses on permanent contracts & -2.55 & .05 \\
\hline & Proportion of nurses experienced emotional abuse & -0.02 & .05 \\
\hline \multirow{2}{*}{$\begin{array}{l}\text { Failure to Rescue } \\
\text { (Pseudo } R^{2}=.10 \text { ) }\end{array}$} & Unanticipated changes in acuity of patients & 1.36 & .02 \\
\hline & Proportion of hours worked by Registered Nurses & -4.97 & .01 \\
\hline
\end{tabular}

\section{Discussion}

The longitudinal study results show that although there had been increased investments in nursing over the 5-year period, they were primarily in specialized nursing units such as critical care and ED, and primarily in metropolitan hospitals. At the same time, there was increased casualization (rates of part-time hours worked) of the nursing workforce and downward substitution, converting nursing positions to assistants in nursing. These findings parallel similar trends in many countries including the USA (Bureau of Labor Statistics, 2008), and may reflect the fact that policy makers believe that ICU/ED nursing work is more difficult than general nursing so more 
staff are provided. Similarly, metropolitan hospitals may be thought to have sicker patients and thus deserve more staff. However, those managing the patient load on general medical/surgical nursing units do not profit from ICU protocols and standards of care, nor from an increased number of intensivists. The care burden of an aging population does not fall on ICUs, it falls on general medical/surgical units where the complexity of care is mostly managed by nursing. Rural/community hospitals must take all comers, especially in an area as vast as New South Wales, and the resource needs of that care burden defy easy measurement. Casualization of nursing staff as a management strategy produces unstable nursing units (Creegan, Duffield, \& Forrester, 2003).

The longitudinal data showed that higher levels of registered nursing staffing (RN and CNS) were associated with lower levels of adverse events as OPSN (decubiti, GI bleeding, physiological/metabolic derangement, pneumonia, pulmonary failure, sepsis, and shock). When OPSN were included in regression models in the study of matched wards, more RN staff still were associated with lower rates of three negative patient outcomes. These ward-level findings buttress hospital level analyses done using the same definitions of OPSN (McCloskey \& Diers, 2005; Needleman, et al., 2001, 2002). Reviews of literature and meta-analyses have emphasized that the relationship between nurse staffing and patient outcomes is not necessarily linear. An important aspect of workload that emerged from the longitudinal part of the study was patient turnover, which contributes to an unstable work environment. The findings about patient turnover and patient acuity support the inclusion of workload as a distinct concept in the model, different from staffing or skill mix. Patient turnover increases transfers of care with the possibility of communication gaps leading to adverse events. Other ways of measuring workload might include number of physician teams to be coordinated, number of patients on contact precautions or in isolation, or other operational variables, all available in hospital-level data. When the findings of the cross-sectional part of the study amplified the longitudinal study findings, workload and work environment variables showed an interpretable pattern. Where nurses perceived an unsafe environment, where resources in the form of leadership and ancillary staff were perceived to be lacking, where the proportion of BSN-prepared nurses was lower, care deteriorated. Tasks were left undone (especially the comforting/teaching ones) and overtime increased.

Kane et al. (2007) argue that attempts to make linear links between nurse staffing and patient outcomes do not account for the contextual variables that could mediate the linear relationships, including especially the ward environment. Because it is not possible to do large sample studies that include unit-specific measures of 
these variables using existing administrative data, we designed a study using longitudinal data with crosssectional amplification. The findings here reinforce previous research which has found relationships between nursing staffing and skill mix and patient outcomes. When workload and aspects of the working environment are added, the picture of ward operations and their consequences becomes more complex. While this study design resulted in complicated data acquisition and reconciliation strategies, a picture of the complexity of modern hospital operations and their effects on patients emerged. Indeed, the variability in nursing wards in an Australian state with a highly centralized public hospital system was a major finding. That there were so many ward-specific differences makes it clear that the operational unit of hospitals is indeed the nursing ward. Hospital, state, or national-level analyses will mask true patterns of care and their consequences.

The results add to the accumulating body of knowledge that suggests that more RN staff are associated with fewer negative patient outcomes as measured by adverse physiological states, and reinforce the necessity to include measures of workload and the working environment in studies of the relationship of nurse staffing to patient outcomes on hospital nursing wards. Where workload was increased through patient turnover and where nurses experienced emotional abuse, care deteriorated. The more unstable the unit was, either through lack of staff, unpredictability of casemix, or difficulties in managing transfers in or out, the more likely it was that nurses were not able to complete their work, and that patients would experience untoward outcomes. Where nurses felt a sense of autonomy or control over their own practice, and an adequacy of resources (staff), they were able to be productive to the limits of the ward's staffing and skill mix. Recent studies of nurse-patient ratios after implementation of legislative mandates have suggested that beyond a certain point, higher nurse staffing ratios may not produce better outcomes (Lang, et al., 2004; Sochalski, Konetzka, Zhu, \& Volpp, 2008). These studies come from a perspective that questions whether policy decisions should mandate staffing ratios on economic grounds. Our results suggest that it is probably not possible to determine perfect staffing systems or nursepatient ratios if the quality of the working environment and workload are not considered.

\section{Limitations}

While the methods and findings for the longitudinal and cross sectional parts of the study stand on their own, combining the findings was much more difficult than anticipated. In the end, it was only possible to match 43 of 80 wards, which constrained analytic possibilities. 
Administrative data on patient encounters are limited by medical record coding, which is in turn limited by original clinical documentation in the medical record. Payroll or scheduling data were available in Australia, but translating the many ways individual hospitals categorized nurses and wards produced different numbers of useable ward months of data across the sample and the years. We compensated for this by using conservative statistical approaches but there is no way to determine how representative the longitudinal data are of nursing hours across the hospitals and years.

The two methods, longitudinal - constrained by Area Health data submissions - and primary, with randomly selected nursing units - produced different proportions of nursing wards across hospital peer groups. The effect of these differences was to emphasize nurse staffing trends in the larger hospitals.

During the conduct of the study, the Incident Information Management System (IIMS) was introduced in NSW (NSW Health and Clinical Excellence Commission, 2005). While adverse events are to be recorded on the patient record as well as entered into the IIMS database, incidents were not always recorded on patient records. This could have resulted in under-reporting of adverse events in both the longitudinal and cross-sectional data.

\section{Conclusions}

Ward environments are much more variable than is revealed in state or hospital level analyses. Ward level data including staffing would not be difficult to obtain for analysis at the individual hospital level in most countries. Attention paid in future research to identifying the data to assess relationships among nurse staffing and workload in terms of particular casemixes, patient acuity, and turnover, the qualities of leadership and management that make a ward "work", and patient outcomes would be profitable not only as a matter of scientific understanding, but also as a matter of public health policy and institutional well-being. 


\section{References}

Adams, A., Lugsden, E., Chase, J., Arber, S., \& Bond, S. (2000). Skill-mix changes and work intensification in nursing. Work, Employment and Society, 14(3), 541-555.

Aiken, L. H., Clarke, S. P., Cheung, R. B., Sloane, D. M., \& Silber, J. H. (2003). Educational levels of hospital nurses and surgical patient mortality. Journal of the American Medical Association, 290(12), 1617-1623.

Aiken, L. H., Clarke, S. P., Sloane, D. M., Lake, E. T., \& Cheney, T. (2008). Effects of hospital care environment on patient mortality and nurse outcomes. Journal of Nursing Administration, 38(5), 223-229.

Aiken, L. H., Clarke, S. P., Sloane, D. M., \& Sochalski, J. (2001). Cause for concern: Nurses' reports of hospital care in five countries. LDI Issue Brief, 6(8), 1-4.

Aiken, L. H., Clarke, S. P., Sloane, D. M., Sochalski, J. A., Busse, R., Clarke, H., et al. (2001). Nurses' reports on hospital care in five countries. Health Affairs, 20(3), 43-53.

Aiken, L. H., \& Patrician, P. A. (2000). Measuring organizational traits of hospitals: The revised nursing work index. Nursing Research, 49(3), 146-153.

Aiken, L. H., Smith, H. L., \& Lake, E. T. (1994). Lower Medicare mortality among a set of hospitals known for good nursing care. Medical Care, 32(8), 771-787.

Aiken, L. H., Sochalski, J., \& Lake, E. T. (1997). Studying outcomes of organizational change in health services. Medical Care 35(11), NS6-NS18.

Aisbett, C. (1999). Formal casemix comparison of hospitals. Paper presented at the Tenth Casemix Conference, Melbourne, Australia.

Australian Bureau of Statistics. (2008). NSW in focus, 2008 (reissue). Retrieved September 20th, 2008, from http://www.abs.gov.au/AUSSTATS/abs@.nsf/allprimarymainfeatures/A69AE58A8429BD25CA2575430015040C?opend ocument

Australian Institute of Health and Welfare. (2008). Australian hospital statistics 2006-07 (No. HSE 55). Canberra, Australia: AlHW.

Baggs, J. G., Schmitt, M. H., Mushlin, A. I., Mitchell, P. H., Eldredge, D. H., Oakes, D., et al. (1999). Association between nurse-physician collaboration and patient outcomes in three intensive care units. Critical Care Medicine, 27(9), 19911998.

Beglinger, J. E. (2006). Quantifying patient care intensity: An evidence-based approach to determining staffing requirements. Nursing Administration Quarterly, 30(3), 193-202.

Boyle, S. M. (2004). Nursing unit characteristics and patient outcomes. Nursing Economic\$, 22(3), 111-119.

Bureau of Labor Statistics. (2008). Occupational Outlook Handbook, 2008-09 edition. Retrieved July 18, 2008, from http://www.bls.gov/oco/ocos083.htm

Chagnon, M., Audette, L. M., Lebrun, L., \& Tilquin, C. (1978). Validation of a patient classification through evaluation of the nursing staff degree of occupation. Medical Care, 16(6), 465-475.

Clarke, S. P. (2007). Hospital work environments, nurse characteristics, and sharps injuries. American Journal of Infection Control, 35(5), 302-309.

Creegan, R., Duffield, C. M., \& Forrester, K. (2003). Casualisation of the nursing workforce in Australia: Driving forces and implications. Australian Health Review, 26(1), 201-208.

Czaplinski, C., \& Diers, D. K. (1998). The effect of staff nursing on length of stay and mortality. Medical Care, 36(12), 16261638.

Dall, T. M., Chen, Y. J., Seifert, R. F., Maddox, P. G., \& Hogan, P. F. (2009). The economic value of professional nursing. Medical Care, 47(1), 97-104.

Diers, D. K., \& Potter, J. (1997). Understanding the unmanageable nursing unit with casemix data: A case study. Journal of Nursing Administration, 27(11), 27-32.

Duffield, C. M., Diers, D. K., Aisbett, C., \& Roche, M. A. (2009). Churn: Patient turnover and casemix. Nursing Economic $\$$, 27(3), 185-191.

Duffield, C. M., Roche, M. A., O'Brien-Pallas, L. L., Diers, D. K., Aisbett, C., King, M. T., et al. (2007). Glueing it together: Nurses, their work environment and patient safety. Retrieved 25th February, 2009, from http://www.health.nsw.gov.au/pubs/2007/pdf/nwr_report.pdf

Estabrooks, C. A., Midodzi, W. K., Cummings, G. G., Ricker, K. L., \& Giovannetti, P. (2005). The impact of hospital nursing characteristics on 30-day mortality. Nursing Research, 54(2), 74-84.

Graf, C. M., Millar, S., Feiteau, C., Coakley, P. J., \& Erickson, J. I. (2003). Patients' needs for nursing care: Beyond staffing ratios. Journal of Nursing Administration, 33(2), 76-81.

Haberfelde, M., Bedecarre, D., \& Buffum, M. (2005). Nurse-sensitive patient outcomes: An annotated bibliography. Journal of Nursing Administration, 35(6), 293-299.

Hyun, S., Bakken, S., Douglas, K., \& Stone, P. W. (2008). Evidence-based staffing: Potential roles for informatics. Nursing Economic\$, 26(3), 151-173.

Kane, R. L., Shamliyan, T. A., Mueller, C., Duval, S., \& Wilt, T. J. (2007). The association of registered nurse staffing levels and patient outcomes: Systematic review and meta-analysis. Medical Care, 45(12), 1195-1204. 
Kovner, C., \& Gergen, P. J. (1998). Nurse staffing levels and adverse events following surgery in US hospitals. Journal of Nursing Scholarship, 30(4), 315-321.

Kramer, M., \& Hafner, L. P. (1989). Shared values: Impact on staff nurse job satisfaction and perceived productivity. Nursing Research, 38(3), 172-177.

Lang, T. A., Hodge, M., Olson, V., Romano, P. S., \& Kravitz, R. L. (2004). Nurse-patient ratios: A systematic review on the effects of nurse staffing on patient, nurse employee, and hospital outcomes. Journal of Nursing Administration, 34(7-8), 326-337.

Lankshear, A. J., Sheldon, T. A., \& Maynard, A. (2005). Nurse staffing and healthcare outcomes: A systematic review of the international research evidence. Advances in Nursing Science, 28(2), 163-174.

Leiter, M. P., \& Laschinger, H. K. S. (2006). Relationships of work and practice environment to professional burnout: Testing a causal model. Nursing Research, 55(2), 137-146.

McCloskey, B. A., \& Diers, D. K. (2005). Effects of New Zealand's health reengineering on nursing and patient outcomes. Medical Care, 43(11), 1140-1146.

McGillis-Hall, L., Doran, D. I., \& Pink, G. H. (2004). Nurse staffing models, nursing hours, and patient safety outcomes. Journal of Nursing Administration, 34(1), 41-45.

Needleman, J., Buerhaus, P. I., Mattke, S., Stewart, M., \& Zelevinsky, K. (2001). Nurse staffing and patient outcomes in hospitals. Boston: Harvard School of Public Health.

Needleman, J., Buerhaus, P. I., Mattke, S., Stewart, M., \& Zelevinsky, K. (2002). Nurse-staffing levels and the quality of care in hospitals. New England Journal of Medicine, 346(22), 1715-1722.

Needleman, J., Kurtzman, E. T., \& Kizer, K. W. (2007). Performance measurement of nursing care: state of the science and the current consensus. Medical Care Research and Review, 64(2 suppl), $10 \mathrm{~S}$.

NSW Health. (2008). Clinical Nurse/Midwife Specialist Grade 1 \& Grade 2 Classifications. Retrieved 15th June, 2009, from http://www.health.nsw.gov.au/policies/pd/2008/pdf/PD2008_044.pdf

NSW Health and Clinical Excellence Commission. (2005). Incident information management system. Sydney.

Numata, Y., Schulzer, M., van der Wal, R., Globerman, J., Semeniuk, P., Balka, E., et al. (2006). Nurse staffing levels and hospital mortality in critical care settings: Literature review and meta-analysis. Journal of Advanced Nursing, 55(4), 435448.

O'Brien-Pallas, L. L., Doran, D. I., Murray, M., Cockerill, R., Sidani, S., Laurie-Shaw, B., et al. (2001). Evaluation of a client care delivery model, part 1: Variability in nursing utilization in community home nursing. Nursing Economic\$, 19(6), 267276.

O'Brien-Pallas, L. L., Doran, D. I., Murray, M., Cockerill, R., Sidani, S., Laurie-Shaw, B., et al. (2002). Evaluation of a client care delivery model, part 2: Variability in client outcomes in community home nursing. Nursing Economic\$, 20(1), 1321,36 .

O'Brien-Pallas, L. L., Thomson, D., McGillis-Hall, L., Pink, G. H., Kerr, M., Wang, S., et al. (2004). Evidence-based standards for measuring nurse staffing and performance: Canadian Health Services Research Foundation.

Rafferty, A. M., Clarke, S. P., Coles, J., Ball, J., James, P., McKee, M., et al. (2007). Outcomes of variation in hospital nurse staffing in English hospitals: Cross-sectional analysis of survey data and discharge records. International Journal of Nursing Studies, 44(2), 175-182.

Sales, A. E., Sharp, N. D., Li, Y.-F., Lowy, E., Greiner, G. T., Liu, C. F., et al. (2008). The association between nursing factors and patient mortality in the Veterans Health Administration: The view from the nursing unit level. Medical Care, 46(9), 938-945.

Sexton, J. B., Hozmueller, C., Pronovost, P. J., Thomas, E. J., McFerran, S., Nunes, J., et al. (2006). Variations in caregiver perceptions of teamwork climate in labor and delivery units. Journal of Perinatology, 26(8), 463-470.

Silber, J. H., Williams, S. V., Krakauer, H., \& Schwartz, J. S. (1992). Hospital and patient characteristics associated with death after surgery. A study of adverse occurrence and failure to rescue. Medical Care, 30(7), 615-629.

Sochalski, J., Konetzka, R. T., Zhu, J., \& Volpp, K. (2008). Will mandated minimum nurse staffing ratios lead to better patient outcomes? Medical Care, 46(6), 606-613.

SPSS Inc. (2003). SPSS for Windows (Version 12.0.1). Chicago: SPSS Inc.

Tourangeau, A. E., Doran, D. M., McGillis-Hall, L., O'Brien-Pallas, L. L., Pringle, D., Tu, J. V., et al. (2007). Impact of hospital nursing care on 30-day mortality for acute medical patients. Journal of Advanced Nursing, 57(1), 32-44.

Unruh, L. (2008). Nurse staffing and patient, nurse, and financial outcomes. American Journal of Nursing, 108(1), 62-71.

Unruh, L., \& Fottler, M. (2006). Patient turnover and nursing staff adequacy. Health Services Research, 41(3), 601-612.

Vahey, D. C., Aiken, L. H., Sloane, D. M., Clarke, S. P., \& Vargas, D. (2004). Nurse burnout and patient satisfaction. Medical Care, $42(2$ suppl), II-57-66. 